\title{
MEDITERRANEAN SECURITY \\ INTO THE COMING MILLENNIUM
}

\author{
Edited by \\ Stephen J. Blank
}

1999

BOOKSTACKS 